\title{
Habitat Suitability Modeling of Endangered Primates in Nigeria: Integrating Satellite Remote Sensing and Spatial Modeling Techniques
}

\author{
Alex 0. Onojeghuo ${ }^{1,2 *}$, Alan G. Blackburn1, Francis Okeke ${ }^{3}$, Ajoke R. Onojeghuo ${ }^{2,4}$ \\ ${ }^{1}$ Lancaster Environment Centre, Lancaster University, Lancaster, UK \\ ${ }^{2}$ Department of Surveying and Geoinformatics, Nnamdi Azikiwe University, Awka, Nigeria \\ ${ }^{3}$ Wildlife Conservation Society, Calabar, Nigeria \\ ${ }^{4}$ Centre for Landscape and Climate Research, University of Leicester, Leicester, UK \\ Email: ${ }^{*}$ lexisgis@yahoo.com
}

Received 18 August 2015; accepted 10 October 2015; published 13 October 2015

Copyright (C) 2015 by authors and Scientific Research Publishing Inc.

This work is licensed under the Creative Commons Attribution International License (CC BY). http://creativecommons.org/licenses/by/4.0/

(c) (i) Open Access

\section{Abstract}

This paper investigates the impacts of forest cover and spatial structure changes on the forest landscape across Afi-Mbe-Okwangwo protected area of Cross River State, Nigeria and its corresponding implication on two endangered primates (Cross River Gorilla and Nigeria-Cameroon Chimpanzee) habitat using satellite remote sensing and modeling techniques. Using remote sensing change detection analysis, the spatial extent and annual rate of deforestation for the study area was determined as 34,620 hectares and $1.5 \%$ respectively (from 2000 to 2014). The protected areas with highest annual deforestation rates were Afi Mountain Wildlife Sanctuary (2.6\%) and Mbe Mountains (2.2\%), both prominent for gorilla and chimpanzee sightings and nests. Further investigations on changes to the forest landscape structure revealed high levels of forest fragmentation across the study area for the 14-year period investigated. As a means of further understanding effects of forest landscapes changes across the study area, a 14-year forward simulation was performed using the Markov model as to determine the spatial extent of futuristic forest cover changes. The results showed that if this current trend of forest cover change continued, 28,121 hectares of forests would be lost to deforestation in 2028 (approximately $16 \%$ of the total landmass of the entire study area). Using Maxent modeling, suitable primate habitats were predicted and the total coverage determined as 30,940 hectares $(54.4 \%$ situated in CRNP-Okwangwo division, $29.4 \%$ in AMWS, $14.3 \%$ in Mbe Mountains and $1.9 \%$ in ARFR). Further analysis revealed 6468 hectares of predicted primate habitat were affected by deforestation in 2014 (21\% of the predicted primate habitats). These results indicate that suitable ${ }^{*}$ Corresponding author. 
primate habitats (particularly for gorillas and chimpanzees) are under immense pressure from deforestation and forest fragmentation. This paper presents a cost effective and time saving approach for determining suitable primate habitats and understanding the effects of forest transition on primate habitat suitability.

\section{Keywords}

\section{Maxent, Remote Sensing, Primates, GIS, Deforestation, Markov, FRAGSTATS}

\section{Introduction}

The negative impacts of forest loss and hunting activities across the world's tropical forests are sources of concern, as it affects the continued existence of endangered primates [1]-[3]. The Afi-Mbe-Okwangwo forest landscape is a biodiversity hotspot with known sightings of four Red List endangered primates namely: the Nigeria-Cameroon Chimpanzee Pan Troglodytes ellioti, Cross River Gorilla Gorilla gorilla diehli, Preuss's guenon Cercopithecus preussi and drill Mandrillus leucophaeus [4]-[6]. The area is also known to have suitable roosting sites for migratory birds [4]. However, this region of great ecological importance is faced with a range of human induced threats to the existing wildlife and forest ecosystem at large. Furthermore, the large and growing population of Cross River State depends greatly on subsistence agriculture, which has over the years resulted in high rates of forest loss and over-exploitation of natural resources [1]. This once undisturbed stretch of tropical forests in Cross River State is faced with diverse threats of deforestation in forms of large commercial plantations of plantain, rubber, cashew and pineapples [7]-[9]. In Africa, primates population have been most affected by loss and modification of forest habitats resulting from factors like intense logging, shifting cultivation, bush burning, over harvesting of fuel wood for commercial and household use, creation of grazing land and clearance for plantation farming [7] [10]-[12]. The interaction of high population growth rates and deforestation rates has caused a significant loss in the spatial coverage of remaining tropical forest landscapes across Africa [13] [14]. The study by [4] noted that primates, such as gorillas, are particularly vulnerable given their reliance on tropical forest habitats, slow rates of reproduction and massive body sizes. Hence, a better understanding of environmental factors such as forest cover distribution, pattern of forest landscape dynamics and modeling of species distribution would prove vital in enhancing conservation and proper management of forest protected areas across Africa.

The combined use of satellite remote sensing and ground truth data has shown to be an effective method of understanding changes in forest landscapes across the world [4] [15]-[18]. Using outputs from remote sensing in form of classified images, a better understanding of forest structure changes is possible, providing valuable results that are crucial to formulating strategies which assist in forest conservation and preservation of existing wildlife. A major problem identified in a number of conservation related studies is the negative impact of forest fragmentation on existing wildlife that relies on forested habitats for survival [19]-[21]. The study [20], assessed levels of forest fragmentation in the conservation of priority landscapes across parts of India using FRAGSTATS analysis. The investigation as to changes in the spatial structure of forest landscape provided a better understanding of forest fragmentation and its impact on protected areas across the study area.

An important component of this study was to perform a forward simulation of forest landscape transition in the study area as a means to create futuristic scenarios based on existing trends of forest cover dynamics. This would provide a direct representation as to the spatial and structural changes of forest landscape in the future, provided the current trend of forest transition continues. With such outputs, it would be particularly useful for wildlife conservation and decision makers involving in the day to day running and management of protected areas across the country. To this end, the Markovian process which had capabilities to model future state of landscapes using the immediate preceding state as a basis for forward prediction [22] was investigated in the study. [23] proposed making use of the cellular automata-Markov Chain model to simulate a counterfactual scenario of evaluating the role of forest conservation and investigate degrees of forest fragmentation protected areas in part of India.

Having a good understanding of wildlife species distribution and identifying factors that influence habitat se- 
lection would greatly assist wildlife conservation and management. Within Afi-Mbe-Okwangwo protected area landscape, delineating the current and potential distribution of endangered species, such as the Cross River Gorillas and Chimpanzees primates are critical to conservation management and planning. Part of this study shall investigate the use of presence-only data and other environmental variables for mapping suitable habitats for endangered primates in the study area. The Maximum Entropy modeling (Maxent), allows for suitable habitat distribution through combined use of presence data and environmental variables [24]-[28]. The advantages of Maxent modeling include high levels of relative insensitivity to positional errors of species location data, nondependence on large datasets for predictive modeling and better performance levels when compared to other predictive modeling techniques [27]. Although we acknowledge the existence of other predictive models, emphasis of this study focuses on use of Maxent model in primate habitat distribution across parts of Nigeria. Since the Maxent modeling technique relies greatly on species presence data, collection of such information should be unbiased in nature and great care must be taken to avoid data duplication [25].

Taking into consideration the afore-mentioned, this study aimed to investigate impacts of forest cover and spatial structure changes on the forest landscape of Afi-Mbe-Okwangwo protected area in Cross River State, Nigeria particularly its corresponding implication on two endangered primates (Cross River Gorilla and Nigeria-Cameroon Chimpanzee) habitat using satellite remote sensing and modeling techniques. The key objectives of the study were: 1) to examine the changes in forest cover and spatial structure across the study area using satellite remote sensing and ground data; 2) to perform predicted forward simulation of forest cover changes across the study area as a means of projecting possible impacts of deforestation on existing forest landscapes; 3 ) to model habitat suitability of endangered primates using a combination of species presence data and other key environmental variables; and 4) to estimate the spatial extent and effects of deforestation on predicted primate habitats.

\section{Materials and Methods}

\subsection{Study Area}

The study area, Afi-Mbe-Okwangwo forest landscape, is composed of four protected areas namely Afi Mountain Wildlife Sanctuary (AMWS), Afi River Forest Reserve (ARFR), Mbe Mountains and Cross River National Park (CRNP) (Okwangwo division) all situated in the northern part of Cross River State (Figure 1). The entire landscape covers an approximate area of 176,835 hectares and is geographically located between latitudes $6^{\circ} 04^{\prime} 19^{\prime \prime}$ to $6^{\circ} 28^{\prime} 35^{\prime \prime}$ and longitudes $8^{\circ} 49^{\prime} 55^{\prime \prime}$ to $9^{\circ} 21^{\prime} 47^{\prime \prime}$.

The AMWS is the westernmost protected area that serves as home to estimated 25 - 30 Cross River Gorilla sightings. The sanctuary created in 2000 was established to protect wildlife in approximately $100 \mathrm{~km} 2$ of lowland and hill forests in the north-western corner of the $380 \mathrm{~km}^{2}$ Afi River Forest Reserve (ARFR) [3]. The protected area is currently managed by the Cross River State Forestry Commission with assistance from the environmental NGO Wildlife Conservation Society (WCS). Other NGOs that have been involved region include Fauna and Flora International, Nigerian Conservation Foundation and Pandrillus. The AMWS is dominated by rocky hills with sparse vegetation and large grasslands making it a suitable roost for migratory European barn swallows (Hirundo rustica). [4] estimates 20 million winter birds, particularly swallows, roost in the suitable grasslands of the AMWS each year. The sanctuary is surrounded by sixteen villages and farms which has led to cases of encroachment beyond its boundaries, scattered logging in the lowland areas, occurrence of forest fires during farm clearing by farmers in farming seasons, poaching of endangered wildlife (such as the Cross River Gorilla, chimpanzee etc.) and over exploitation of non-timber forest products such as herbs for commercial and household use [1] [3] [4] [29].

To the east of the Afi Mountains and adjourning the ARFR is the Mbe Mountains protected area, a forest dominated hilly landscape with sightings of gorillas since 1983 was established a wildlife sanctuary in 2000 [30]. It covers an estimate area of $100 \mathrm{~km}^{2}$ and has hills rising to elevation of 900 metres. To the northern, western and southern parts of Mbe Mountains are nine villages (namely, Kanyang 1, Kanyang 2, Bamba, Abo Mkpang, Abo Obisu, Abo Ogbagante, Bokalom, Wula 1 and Wula 2) which have led to problems of encroachment by surrounding communities. The Mbe Mountains is an important corridor between AMWS and east of the CRNP (Okwangwo Division). The Mbe Mountains has been managed as a community wildlife sanctuary by the Conservation Association of the Mbe Mountains (CAMM) established by the earlier mentioned nine communities. The community wildlife sanctuary is managed by CAMM and supported by the CRS Forestry Commission and Wildlife Conservation Society (WCS). As is the case with AMWS, similar challenges from agricultural active- 


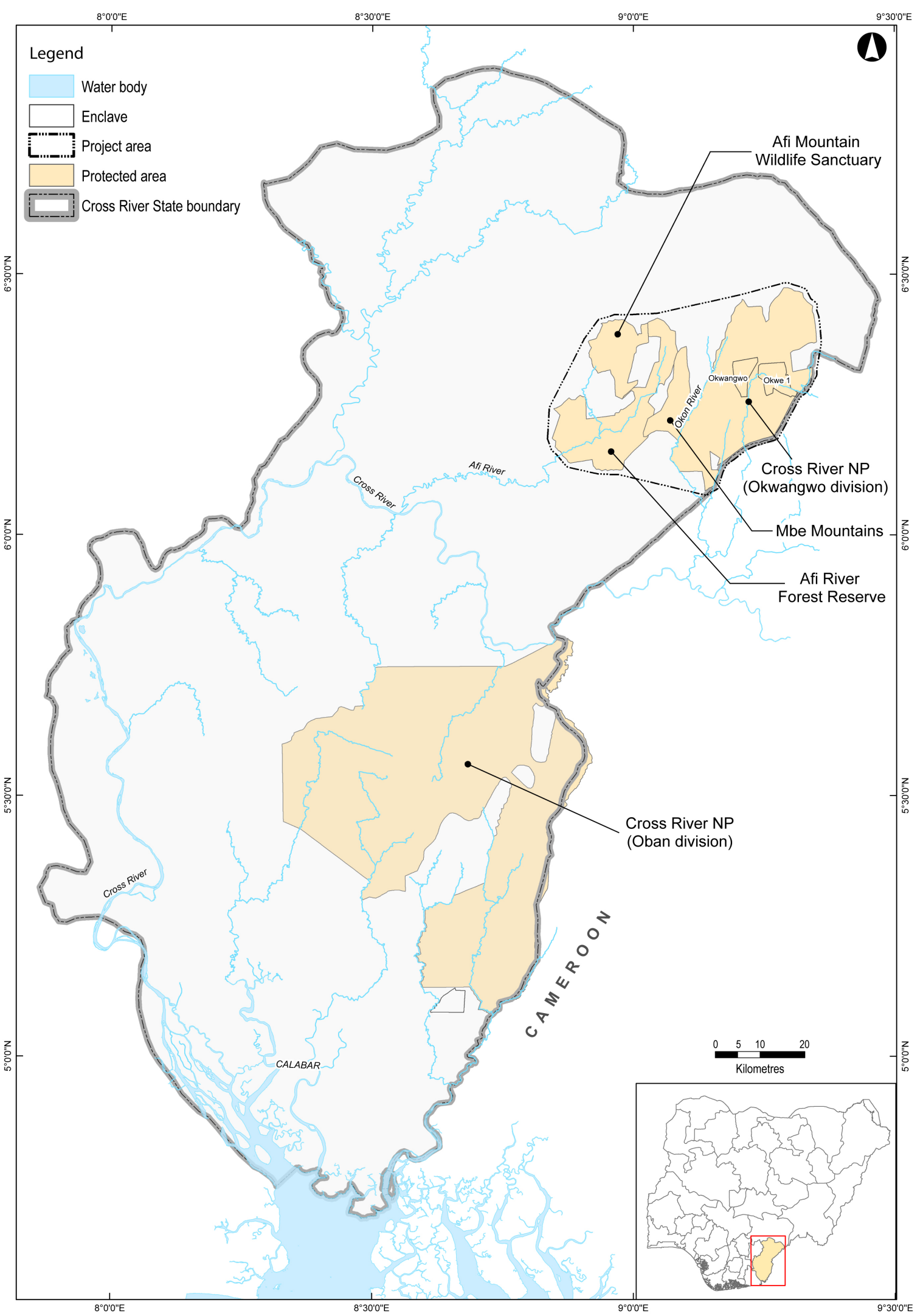

Figure 1. Map of study area showing protected areas investigated and an insert map of Nigeria showing Cross Rivers State. 
ties, poaching, bush burning and fragmentation of existing forest landscapes are key issues of concern in the protected area. [30] confirmed the severity of threats from hunting, farm encroachment, fire and logging as threats to the ecological integrity of the landscape which left unchecked could affect the continued existence of the Cross River Gorilla and other primates present.

Further to the east of Mbe Mountains, divided by the Okon River is CRNP Okwangwo Division. The CRNP located in south eastern Nigeria consists of two divisions, the Oban division to the south of Cross River state and the Okwangwo division to the north as shown in Figure 1. The Okwangwo division of the CRNP, created in 1991, covers an approximate area of $4000 \mathrm{~km}^{2}$ and comprises of the former Boshi, Okwangwo, Boshi Extension Forest reserves and some inhabited enclaves (Okwangwo and Okwe 1) [2] (Figure 1). The CRNP Okwangwo division landscape, dominated by mixture of primary and secondary high forests and savanna woodland formations, has a high biodiversity particularly with respect to primates like the Cross River Gorilla [31]. Although the wildlife in the park are in theory under protected status, hunting in the park is widespread and cases of fire in the montane forests on the edge of the Obudu Plateau a reoccurring event [3]. The gorilla habitats in the CRNP (Okwangwo division) are under immense threat from farming encroachment as the population within both enclaves has greatly increased over the years.

\subsection{Field Data Collection}

The field data on endangered primates (gorillas and chimpanzees) presence across the study area was collected using cyber-tracking technology employed by patrol officers of WCS and CRSFC [32]. The signs of gorilla and chimpanzee presence were based on vocalisation; presence of nests, food remains, dung and direct encounters. The use of cyber tracking based systems was introduced in the Mbe Mountains in 2009 and has since allowed for ease in tracking gorillas across the protected area since [32]. Other sources of endangered primate sightings were obtained from the WCS annual reports available on the official website (http://www.wcsnigeria.org/). The gorilla and chimpanzee presence data from 2011 to 2014 was used for this study. Past studies on gorilla distribution in Cross River observed that combining earlier surveys did not alter the current distribution of the primates, as recent surveys showed that all earlier known areas were still occupied [4].

\subsection{Forest Cover Mapping Using Remote Sensing}

The change in the forest landscape across the study area was performed using satellite remote sensing data for two epochs (2000 and 2014). For this study Landsat 7 Enhanced Thematic Mapper (ETM+) with World Reference System path 187, row 056 (10 December 2010) and UK-DMC satellite data (7 January 2014) were used. The Landsat data was downloaded from the United States Geological Survey GLOVIS web-page (http://glovis.usgs.gov/) while the UK-DMC satellite data was supplied by Nigeria Space Agency, NASRA (National Space Research and Development Agency), based on sharing agreement with UK partners (Disaster Monitoring Constellation Company, DMCii). The Landsat image was processed to Level 1 Terrain-corrected, implying it was already ortho-rectified making it a suitable product for direct image-to-image comparison in change detection analysis. Similarly the UK-DMC satellite image was radiometrically and geometrically corrected. Since the images were already radiometrically and geometrically corrected on delivery, the Landsat and UK-DMC images were atmospherically corrected [33] and the digital numbers converted to ToA (i.e. Top of Atmosphere Reflectance) [34] [35]. This conversion process was done to remove all forms of noise present in the satellite images (such as instrument error, errors from view changes during data acquisition and effects of illumination geometry) [34] [36] [37]. A similar approach was implemented on the UK-DMC image used in the study. Before image classification, Landsat bands with same spectral ranges as the UK-DMC image were selected for input during image classification (Figure 2).

For this study, the supervised maximum likelihood classifier (MLC) was applied to each satellite image. A total of six broad classes were used in the study, based on the Intergovernmental Panel on Climate Change land use classification scheme [38]. The six broad classes comprised of forestland, cropland, grassland, wetlands, settlements and other land classes. For purpose of this study theses classes were further re-categorized into two distinct classes namely Forest and Non-forest. The process of image classification and accuracy assessment was performed using independent training and testing data. The training and ground truth data were obtained using a variety of sources namely Google Earth, GPS (global positioning system) data over the study area, historic/recent aerial photographs and visual interpretation of the satellite images. 


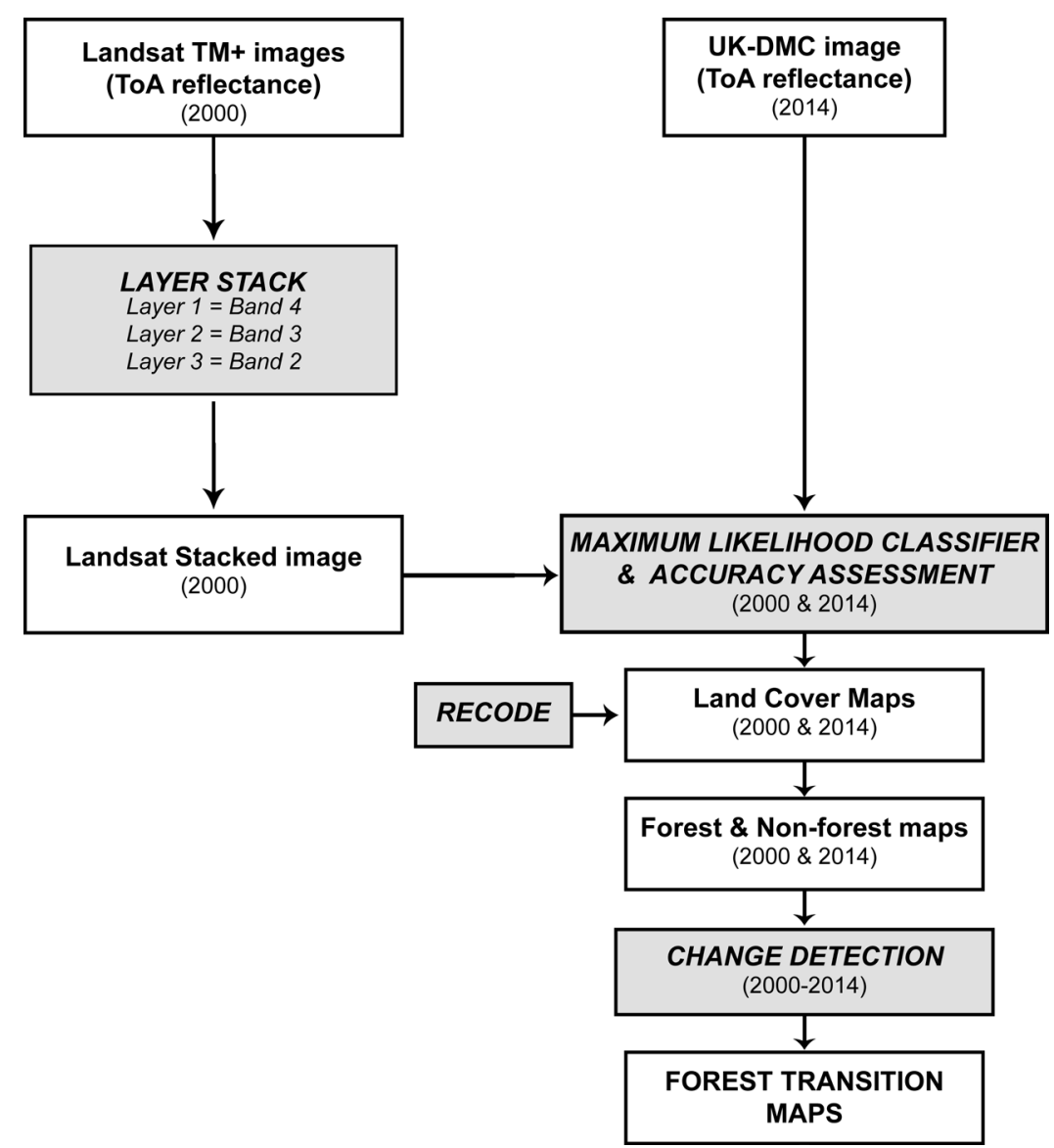

Figure 2. Procedure for post classification comparison using Landsat and UK-DMC satellite images.

\subsection{Forest Cover Change Analysis}

In this study, the IDRISI Selva Land Cover Modeler was used to analyses forest cover change over the study area. Using results of the forest cover maps for 2000 and 2014, forest cover change maps across the protected areas were determined for 2000 to 2014. The forest cover change maps for both time intervals showed deforested, unchanged forest and afforested landscapes classes. In order to calculate, the annual deforestation and forest changes for the two time periods were used.

\subsection{Spatial Dynamics of Forest Landscape and Predictive Modeling}

The open source software, FRASTATS (version 4.3.1.603), [39] was used to calculate the landscape and class metrics needed to better understand the spatial structure of forest cover classifications. The class metrics used in this study included the number of patches (NP), mean patch area (MPA) and patch density (PD) (which is the number of patches of a patch type divided by the total landscape area).

An important component of this study, with particular emphasis on the management of protected areas and eventual benefits to endangered primate habitats, was predicting the future status forest landscapes across the study area using current trends of forest cover transition. To this end, the Markov Chain Analysis and Cellular Automata Analysis (CA_MARKOV) module in IDRISI Selva was used to model forest cover scenario over a 14-year future projection (i.e. from 2014 to 2028). The Markovian process models the future state of any chosen landscape using the immediate preceding state as the basis for forward prediction [22]. For this study, the forest cover maps for 2000 and 2014 were used to model future predictions of forest cover over a 14-year period. Using the forest cover maps for 2000 and 2014 as inputs, the MARKOV module was used to produce the transition probability matrices and conditional probability images. To implement the CA_MARKOV module, the transition area text file, transition suitability image and 2014 forest map were used to generate a 14-year forward si- 
mulation of forest cover. The Cellular Automata iteration was specified as 14, allowing the model to be based on 1-year increments. The default cellular Automata filter of $5 \times 5$ was used for the study.

\subsection{Maximum Entropy Modeling of Endangered Primates in Cross River State}

The Maximum Entropy Distribution (Maxent) [26] [27] was used to model the presence of endangered gorilla and chimpanzee primates across the study area. Maxent is a machine learning programme that utilises maximum entropy to estimate species distribution probabilities' using the presence only data and environmental variables (categorical or continuous) [26]. For this study endangered primates' presence data across the study area and environmental variable (continuous and categorical) layers were used as inputs into the modeling process. The open source software Maxent version 3.3.3k (http://www.cs.princeton.edu/ schapire/maxent/) was used to generate estimates of probabilities for primates presence varying from 0 to 1 (where 0 is the lowest and 1 the highest probability respectively). The presence data, Global Positioning System (GPS) positions of gorilla and chimpanzee nests and sightings for 2009 and 2013 were sample layer inputs used in Maxent to model potential distribution of environmental suitability for the endangered primates. Topographical data used in modeling was taken from the Shuttle Radar Topography Mission Digital Elevation Model (SRTM DEM). The SRTM DEM was downloaded from the Global Land Cover Facility (GLCF) website (http://glcfapp.glcf.umd.edu:8080/esdi/).

The modeling of environmental suitability for endangered primates using the presence data of gorilla and chimpanzee sightings and nests and three key environmental variables namely, DEM (for terrain information), Slope map (derived from the DEM) and forest cover map of the study area. The recommended default values for maximum iteration numbers $(50)$, convergence threshold $(100,000)$ and regularization values $(10,000)$ were used. The random test percentage of value used was 30 (meaning that $30 \%$ of the presence data was used for validation while $70 \%$ for training of the model). For analysis a threshold was specified to help perform binary predictions of habitat suitability conditions with suitable habitats predicted above such threshold and unsuitable indicated as below. In this study a convergence threshold of 0.00001 was used with maximum iterations of 500 . The ASCII raster outputs of predicted primate habitats were further analyzed using ESRI ArcGIS software version $10.2[40]$.

\section{Results and Discussions}

\subsection{Classification Accuracy Results}

The overall land cover classification accuracy results were approximately 89 percent (2000) and 91 percent (2014) respectively. Table 1 presents the classification accuracy reports for the classifications performed. The classification accuracy results were within VCS REDD Methodologies specification [41].

\subsection{Changes in Forest Cover and Spatial Structure}

The classification result shows that total forest cover for the entire study area was 152,509 hectares in 2000 and 129,339 hectares in 2014 (Table 2). The total area of forest cover across the project area landscape declined from $86 \%$ in 2000 to $73 \%$ in 2014. Overall, the four protected areas experienced a general decline in the spatial

Table 1. Accuracy assessment results showing user accuracy (UA), producer accuracy (PA) and overall accuracy (OA) generated for classified images.

\begin{tabular}{|c|c|c|c|c|}
\hline \multirow{2}{*}{ Land Use } & \multicolumn{2}{|c|}{$2000($ ETM+) } & \multicolumn{2}{|c|}{2014 (UK-DMC) } \\
\hline & UA (\%) & PA (\%) & UA (\%) & PA (\%) \\
\hline Forest & 87.1 & 95.7 & 91.8 & 88.2 \\
\hline Farmland & 88.6 & 87.8 & 90.9 & 86.2 \\
\hline Grassland & 93.6 & 96.7 & 91.7 & 94.3 \\
\hline Wetland & 86.4 & 88.4 & 90 & 87.8 \\
\hline Settlement & 100 & 54.6 & 93.3 & 96.6 \\
\hline Other land & 100 & 100 & 86.7 & 100 \\
\hline$O A(\%)$ & \multicolumn{2}{|c|}{89.4} & \multicolumn{2}{|c|}{90.8} \\
\hline
\end{tabular}


cover of forest landscape for the 14-year period investigated (Table 2).

The forest cover transition results indicated that overall deforestation for the study area from 2000 to 2014 was 34,620 hectares (Table 3). The total forest landscape that remained unchanged and afforested for the same period were 117,730 hectares and 11,574 hectares respectively. In terms of percentage landmass, $13.3 \%$ of the total forest landscape was deforested over the entire study area. Amongst the four protected areas, the most affected by deforestation were AMWS and Mbe Mountains with annual deforestation rates of $2.6 \%$ and $2.2 \%$, followed by CRNP (1.1\%) and ARFR (1.5\%). The AMWS and Mbe Mountains, both known to have gorilla and chimpanzee sightings, are under immense pressure from illegal logging, encroachment farming and bush burning. The recent WCS annual report (2014) on AMWS and Mbe Mountains identified rise in the number of hunting incidents in the area, a major threat to the existence of endangered primate population. Furthermore, the close proximity of surrounding communities to the primate habitats has further heightened the pressures of farming encroachment and hunting activities, (particularly in forms of wire snares across the sanctuary). These factors have greatly contributed to the rise in deforestation and consequent disturbance of the gorilla and chimpanzee habitats across the protected area.

Using spatial metrics measures (NP, PD and MPA) over time, the changes in spatial structure over the 14-year period was investigated for the study area The NPs for the entire study area increased from 1255 in 2000 to 2843 in 2014. Similarly, the PD of the entire study area increased from 0.48 in 2000 to 1.12 in 2014 while MPA decreased from 122 hectares (in 2000) to 46 hectares (in 2014) (Table 2). The implication of these results was that the forest landscape across the study area experienced high levels of forest fragmentation over the 14-year period. Results of spatial structure dynamics for all four protected areas indicated that there were significant rises in NP and PD and a general decline in MPA (particularly for Mbe Mountain which experienced a sharp MPA decline from 4472 hectares in 2000 to 48 hectares in 2014). The effects of large decline in forest cover and increased levels of forest fragmentation over the 14-year period are indications of habitat loss, decreased connectivity of remaining vegetation (which prevents migration and movement of primates) and reduction in forest patch sizes (unsuitable for primate habitation). Other key deforestation drivers that have ravaged the Afi-MbeOkwangwo landscape include over-exploitation of non-timber forest products and occurrence of forest fires (a common practice in seasonal farming activities in the lowland forests) [1] [3] [4]. The combined effects of the afore-mentioned drivers of deforestation are serious threats to the conservation of the forest ecosystem, upon which existing primates depend for survival. Hence, the major challenge of the Cross River State Government and Nigeria at large is the establishment of suitable measures to combat or possibly mitigate these effects of de-

Table 2. Results of spatial structure changes for forest landscape in Afi-Mbe-Okwabgwo protected areas from 2000 to 2014.

\begin{tabular}{cccccccccc}
\hline \multirow{2}{*}{ Zone } & \multicolumn{2}{c}{ Forest Cover (ha) } & \multicolumn{2}{c}{ Number of Patches } & \multicolumn{2}{c}{$\begin{array}{c}\text { Patch Density } \\
\text { (no. per 100 ha.) }\end{array}$} & \multicolumn{2}{c}{ Mean Patch Area (ha) } \\
\cline { 2 - 10 } & $\mathbf{2 0 0 0}$ & $\mathbf{2 0 1 4}$ & $\mathbf{2 0 0 0}$ & $\mathbf{2 0 1 4}$ & $\mathbf{2 0 0 0}$ & $\mathbf{2 0 1 4}$ & $\mathbf{2 0 0 0}$ & $\mathbf{2 0 1 4}$ \\
\hline Project area & 152,509 & 129,339 & 1255 & 2843 & 0.48 & 1.12 & 121.52 & 45.49 \\
AMWS & 9715 & 7418 & 76 & 474 & 0.35 & 2.18 & 127.83 & 15.65 \\
ARFR & 27,033 & 22,315 & 113 & 338 & 0.13 & 0.39 & 239.23 & 66.02 \\
Mbe Mountains & 8944 & 6728 & 2 & 141 & 0.01 & 0.67 & 4475.24 & 47.72 \\
CRNP (Okwangwo) & 61,828 & 53,614 & 80 & 496 & 0.06 & 0.37 & 772.85 & 108.09 \\
\hline
\end{tabular}

Table 3. Results of forest cover transition for the Afi-Mbe-Okwangwo forest landscape from 2000 to 2014.

\begin{tabular}{|c|c|c|c|c|c|c|c|c|}
\hline Zone & $\begin{array}{c}\text { Deforested } \\
\text { (ha) }\end{array}$ & $\begin{array}{l}\text { Unchanged } \\
\text { forest (ha) }\end{array}$ & $\begin{array}{l}\text { Afforested } \\
\text { (ha) }\end{array}$ & $\begin{array}{c}\text { Deforested } \\
(\%)\end{array}$ & $\begin{array}{l}\text { Unchanged } \\
\text { forest (\%) }\end{array}$ & $\begin{array}{c}\text { Afforested } \\
(\%)\end{array}$ & $\begin{array}{c}\text { Annual } \\
\text { deforestation } \\
\text { rate }(\%)\end{array}$ & $\begin{array}{l}\text { Annual rate of change } \\
\text { in forest cover }(\%)\end{array}$ \\
\hline Project area & 34,620 & 117,730 & 11,574 & 13.26 & 45.09 & 4.46 & 1.48 & 0.51 \\
\hline AMWS & 3229 & 6486 & 933 & 14.84 & 29.80 & 4.29 & 2.61 & 0.84 \\
\hline ARFR & 5559 & 21,474 & 830 & 6.43 & 24.85 & 0.96 & 1.48 & 0.59 \\
\hline Mbe Mountains & 2311 & 6634 & 94 & 10.92 & 31.35 & 0.45 & 2.19 & 0.88 \\
\hline CRNP (Okwangwo) & 9623 & 52,196 & 1388 & 7.17 & 38.89 & 1.03 & 1.06 & 0.44 \\
\hline
\end{tabular}


forestation across existing protected areas.

To this end, the Nigerian Government is actively involved in the United Nations REDD+ (Reducing Emissions from Deforestation and Forest Degradation) programme aimed at preserving existing forest landscape across the country, particularly forest dependent communities [42]. As part of the REDD+ programme in Nigeria, portions of Afi-Mbe-Okwangwo protected areas have been assigned as one of the three main REDD pilot sites for Cross River State. The implementation of the REDD+ programme across the state would facilitate sustainable management of forest landscape and its resources whist promoting wildlife conservation. Other approaches include creating public awareness on the need to refrain from killing endangered primates and avoidance of human activities such as agricultural encroachment, forest fires, illegal logging and over-exploitation of non-timber forest products. Figure 3 shows the forest cover (2000 and 2014) and forest transition (2000-2014) maps of the entire study area.

\subsection{Forest Cover Forward Simulation}

Figure 4(a) shows the spatial extent of forest cover across the entire study area, including the four protected areas from 2000 to 2028. The results show that for the entire study area, forest landscape experienced a gradual decline over the 28 year period. The spatial extent of forest decline from 2000 to 2014 and 2014 to 2028 were 23,170 hectares and 41,338 hectares respectively. The results of forest landscape decline were representative of approximately 15\% and 27\% of the earlier forest cover in 2000. Figure 4(c) and Figure 4(d) show the 2014 forest cover map and 2028 forward simulated forest cover map of the study area. At a glance there's an obvious decline in the spatial coverage of forest cover in 2028.

The results of forest cover change analysis for the entire study area based on the 2014 and 2028 predicted forest maps showed that 28,121 hectares of forest cover would be deforested. The spatial extent of unchanged forest and afforested landscape between 2014 and 2028 would be 101,183 and 9988 hectares respectively. These
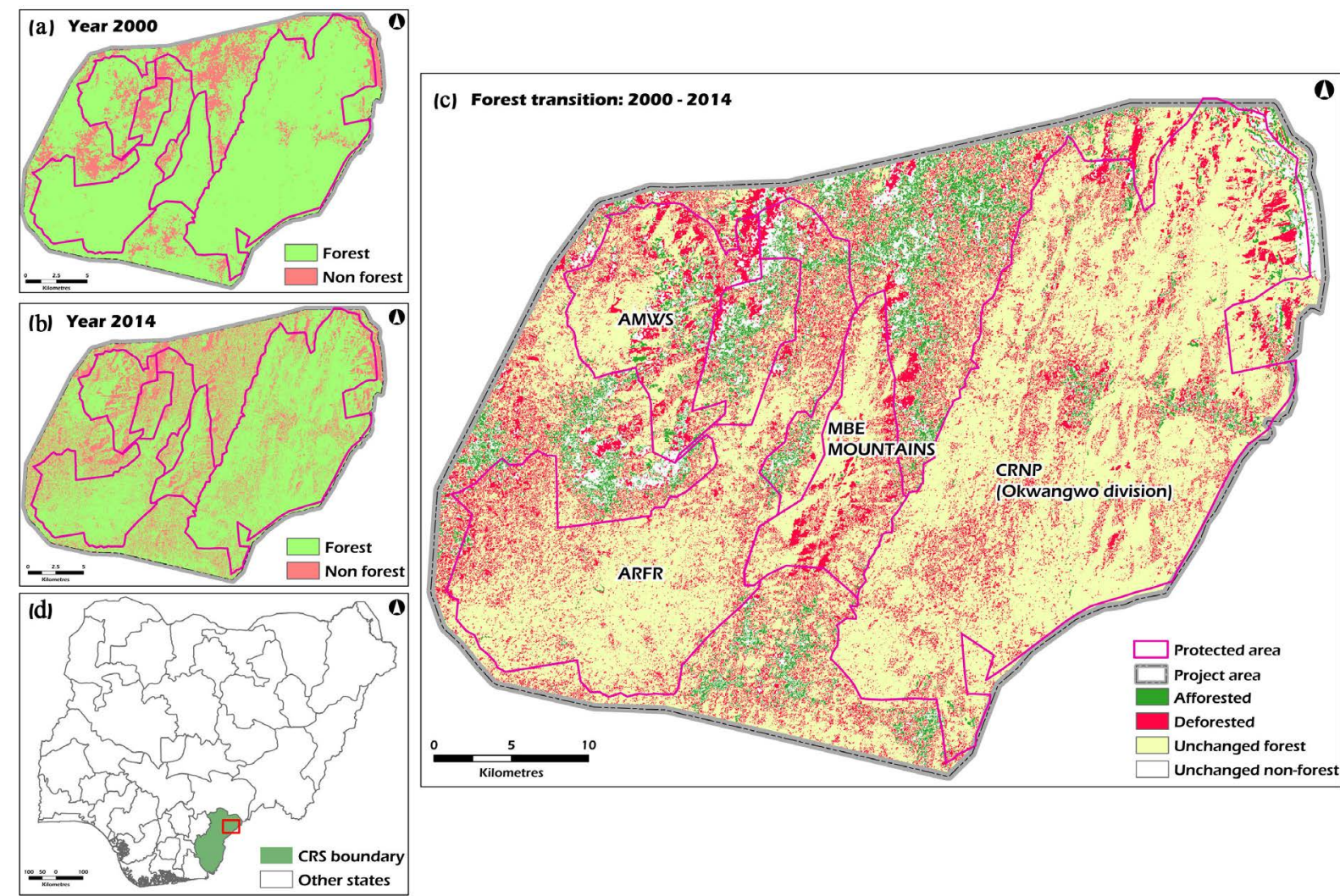

Figure 3. Map of study area showing: (a) Forest cover for 2000; (b) Forest cover for 2014; (c) Forest transition for 2000 to 2014 indicating deforested, unchanged forests, afforested and unchanged non forest landscapes across Afi-Mbe-Okwangwo protected areas in Cross River State; and (d) Insert map of Nigeria showing the study area. 

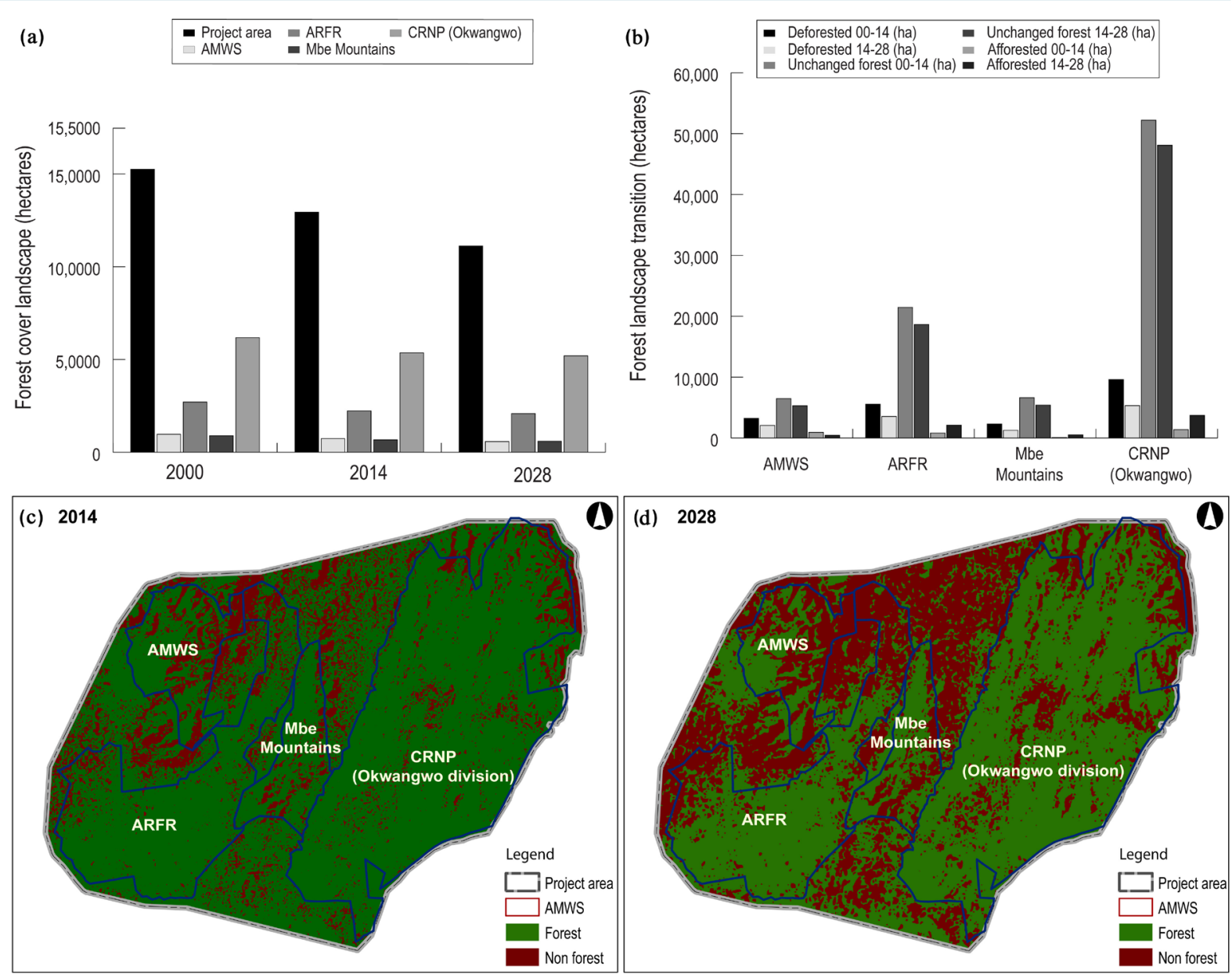

Figure 4. Results of forest transition analysis showing (a) Graph of forest cover landscape for 2000, 2014 and 2028 across study area; (b) Graph of forest transition across study area for 2000-2014 and 2014-2028, indicating deforested, unchanged forest and afforested landscape; (c) Forest cover map of 2014; and (d) 2028 predicted forest cover map generated using Markov module.

predicted results are based on the current trend of forest cover change driven by current forest management practices and pressures from human activities (such as farming encroachment, bush burning and illegal logging). Figure 4(c) shows forest landscape transition highlighting deforested, unchanged and afforested landscapes (for 2000 to 2014 and 2014 to 2028) across the protected areas. Overall, the results show that forest cover transition across the study area is prone to high levels of deforestation particularly outside and within the protected areas (Figure 4(d)). Given the current trend of forest transition, measures should be put in place to mitigate associated threats to endangered primates and human population.

\subsection{Habitat Suitability Modeling of Endangered Primates Using Maxent}

The omission and predicted area plots of the endangered primates (Figure 5) show how testing and training omissions and predicted areas vary with the choice of cumulative threshold. Figure 5(a) and Figure 5(b) showed that the omission on test samples (for both primates) was a very good match to the predicted omission rate. Figure 5(c) and Figure 5(d) showed the receiver operating curve (ROC) for both training and test data used in the modeling process. The red (training) line shows the "fit" of the model to the training data while the blue (testing) indicated the fit of the model to the testing data (note, this is the real test of the models predictive power). Given that the blue line in graph 5(c) and graph 5(d) were towards the top left of the graph, it was an indication that the model was better at predicting the presence contained in the test sample of the data [43]. The accuracy of the predictive modeling for both primates was determined by the test area under the ROC (AUC). 
(a)

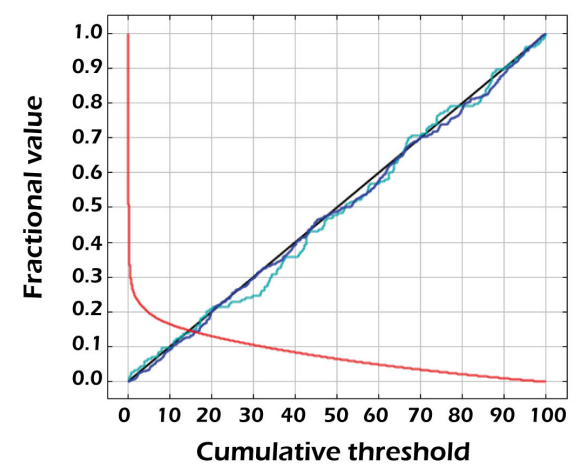

(c) Sensitivity vs. 1 - Specificity for Gorilla

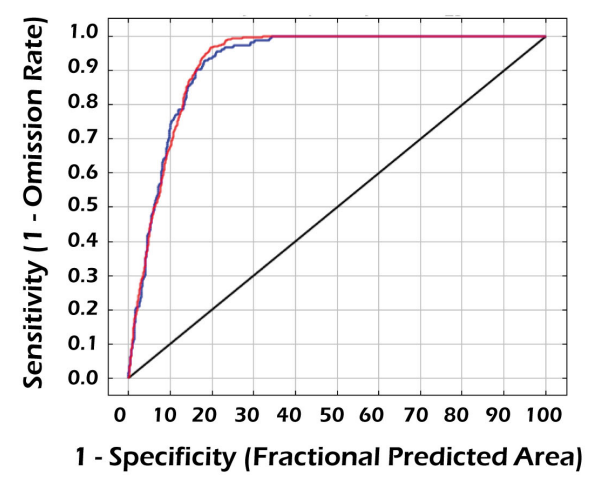

$(b)$

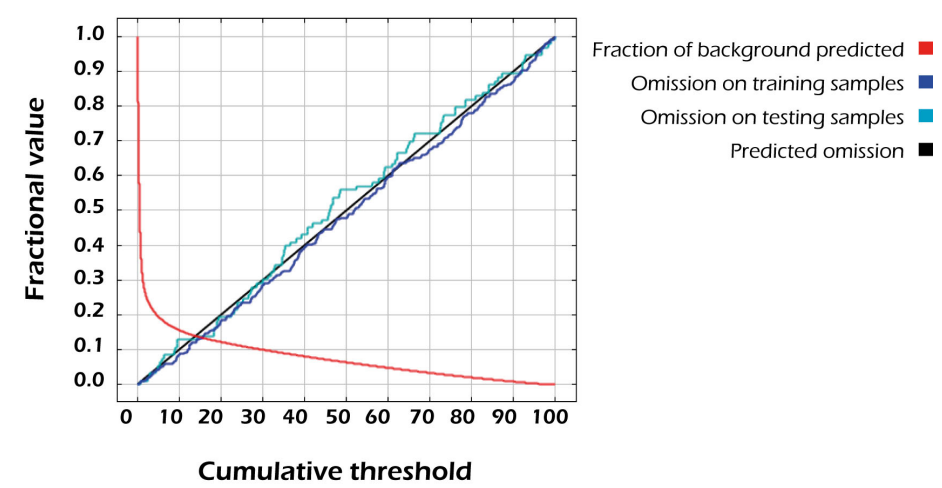

(d)

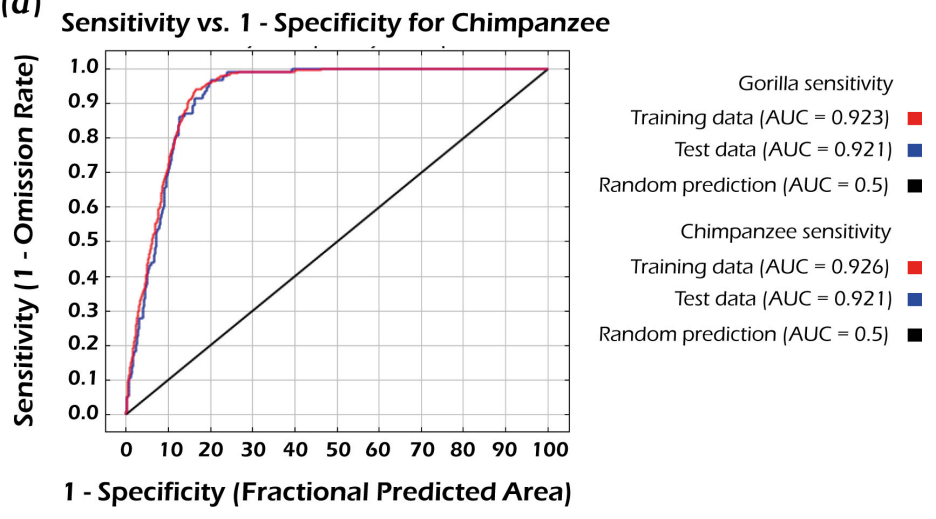

Figure 5. Results of statistical analysis of Maxent modeling for endangered species (Cross River Gorilla and Nigeria-Cameroon Chimpanzee) habitat suitability results of forest transition analysis showing (a) Graph of forest cover landscape for 2000, 2014 and 2028 across study area; (b) Graph of forest transition across study area for 2000-2014 and 2014-2028, indicating deforested, unchanged forest and afforested landscape; (c) Forest cover map of 2014; and (d) 2028 predicted forest cover map generated using Markov module.

The AUC and standard deviation for the modeled prediction of gorillas and chimpanzees habitats were 0.921 (standard deviation 0.006) and 0.921 (standard deviation 0.007) respectively. The gorilla suitability habitat modeling was performed using 359 presence records for training and 153 for testing. For the chimpanzee habitat suitability modeling 217 presence records was used for training and 93 for testing. The environmental variables used in the model included the study area DEM, classified forest map and slope map datasets.

During the training phase of species prediction modeling Maxent software keeps track of environmental variables that contribute to fitting the model. Consistent with ecological knowledge the model predicted that Cross River Gorilla and chimpanzees are found mostly in forested areas (particularly tropical high and montane forests) in mountainous locations across the site. Figure 6(a) and Figure 6(b) show the predicted habitat suitability map outputs of endangered gorilla and chimpanzee primates generated using presence data and key environmental variables in Maxent modeling software. The most important variables in order of importance for both primates as indicated by the Maxent model were DEM, Slope derived map and Forest map of study area.

\subsection{Effect of Deforestation on Predicted Primates Habitat}

The raster datasets showing predicted primate habitats generated using Maxent model were imported into ArcGIS software for further analysis and visualization. The raster outputs were reclassified to binary images showing only predicted primate habitats with possible probability of occurrence (i.e. 0.4 - 1.0) (Figure 6(c)). The binary images were digitized and compared with current and historic primate presence data. The results indicated that the total coverage of predicted suitable habitat for endangered primates over the entire study area was 30,940 hectares (54.4\% situated in CRNP-Okwangwo division, 29.4\% in AMWS, 14.3\% in Mbe Mountains and $1.9 \%$ in ARFR). The spatial coverage of modeled primate habitats for both gorillas and chimpanzees for 

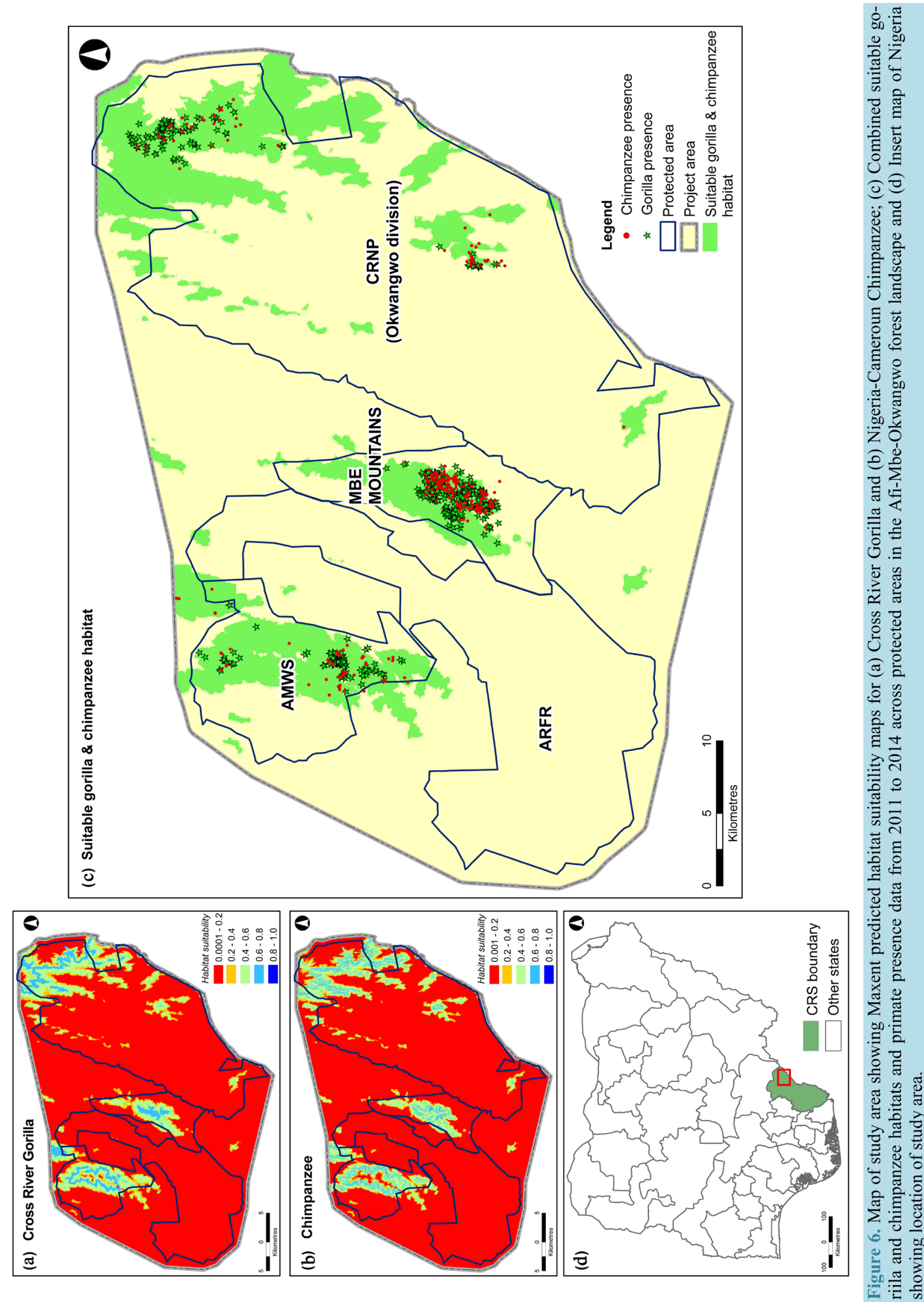
AMWS, ARFR, Mbe Mountains and CRNP (Okwangwo division) were approximately 9094 hectares, 573 hectares, 4428 hectares and 16,846 hectares respectively. These results would prove vital in the effective management and development of conservation plans for endangered primate habitats across the study area required by wildlife conservation organizations and the State government.

Following the modeling of suitable gorilla and chimpanzee habitats, the authors investigated the effects of deforestation trends (2000-2014) on the spatial coverage of predicted primate habitats across the study area. Using spatial analysis techniques in ArcGIS, the forest transition map (Figure 3(c)) and predicted primate habitat map (Figure 6(c)) were reclassified to binary images, each having two classes (deforestation map with $1=$ deforested landscape $\& 0=$ others landscape and primate habitat map with $1=$ primate habitats $\& 0=$ others habitats). Using the afore-mentioned binary raster, a map showing deforestation hotspots across the predicted primate habitat were generated (Figure 6(c)). The results indicated that approximately 6468 hectares of predicted primate habitats were affected by deforestation (21\% of the predicted forested primate habitat) in 2014 . The effects of deforestation and forest fragmentation on the predicted primate habitats reflects the poor management of forest landscape in the protected areas across the study area, justifying the urgent need for existing management practices across the protected areas to be reviewed

\subsection{Implication of Forest Transition and Human Activities on Primates Habitat and Conservation}

The high levels of forest fragmentation across the four protected areas investigated in this study are largely dependent on the current prevailing agricultural practices across the region. The presence of intensified pressure from agricultural encroachment by surrounding villages and communities are key catalysts to the disturbance of existing gorilla and chimpanzee habitats. Over the years the combined effects of forest fragmentation and deforestation has resulted in extensive restriction of primates to isolated and highly fragmented forest patches. This pattern of forest transition combined with uncontrolled hunting in protected areas such as the CRNP (Okwangwo division) has resulted in rapid loss of endangered primates (particularly gorillas and chimpanzees) and in drastic cases extinction of some wildlife species such as the grey-cheeked mangabey (Lophocebus albigena) and crowned guenon (Cercopithecus pogonias) [2] [44]. The problems of hunting and agricultural encroachment are further heightened by the presence of large enclaves in CRNP (Okwangwo division). Similar occurrences are observed in AWFS, ARFR and Mbe Mountains.

In the Mbe Mountains, a key catalyst asides from the above mentioned factors, is the presence of the Ikom-Obudu highway which traverses across Ago Ogbagante, Kayang-1, Kayang-2, Wula-1 and Wula-2 communities. Results of past studies [2] [4] and current interviews have noted a distinct pattern in forest clearance along the Ikom-Obudu highway for agricultural practice by surrounding communities.

The devastating impact of deforestation and other human related activities on remaining forest landscape and wildlife (in particular endangered primates) justifies the need for Cross River State (CRS) Government (in collaboration with the National Government) to put in place mitigative measures and policies/laws that would protect all wildlife and forests. In this regard, the CRS government on February 2014 established a mobile court under the CRSFC charged with the responsibility of prosecuting any individual found guilty of killing or hunting any animal (or endangered species) as listed in the CRS Forestry Commission Law No. 3 of 2010 [45]. Another avenue explored by CRS is the implementation of the UN-REDD+ programme. In 2010 CRS Government demonstrated its commitment to the REDD+ programme by enacting a deforestation moratorium, which is still in force till date, banning all forms of logging in the state [46] [47].

\section{Conclusions}

The study has demonstrated the use of remote sensing data and techniques combined with various modeling approaches to understand effects of forest cover transitions on the spatial structure and prediction of suitable primate habitats. The results show that suitable habitats for gorillas and chimpanzees are under immense pressure from deforestation and high levels of forest fragmentation. Forest change analysis results showed that the overall extent of deforestation across the study area (2000 to 2014) was 34,620 hectares with annual deforestation rate of $1.5 \%$. The protected area with the highest annual deforestation rates were AMWS (2.6\%) and Mbe Mountains (2.2\%), both prominent for gorilla and chimpanzee sightings and nests. The key drivers of deforestation across the study area were identified as illegal logging, over exploitation of non-timber forest products, hunting, farm 
encroachment, and forest fires. Further investigations as to changes in forest landscape structure revealed presence of high forest fragmentation levels, factors that had adverse negative effects on endangered primate and other wildlife habitat. As a means of further understanding the effects of the current forest cover transition trends, a forward simulation of forest landscape was performed for a 14-year forward prediction. The results showed that if the current trend of forest cover changes continued, a total of 28,121 hectares of forest cover would be deforested in the 2028 (approximately 16\% of the total landmass of the entire study area). Using Maxent, suitable primate habitats were modeled and the total coverage of predicted habitat was estimated to be 30,940 hectares (54.4\% situated in CRNP-Okwangwo division, 29.4\% in AMWS, 14.3\% in Mbe Mountains and $1.9 \%$ in ARFR). Further analysis as to the extent of deforestation in the predicted primates habitat revealed that 6468 hectares of forest cover had been deforested in 2014 (an estimated 21\% of the predicted primate habitats). These results show that suitable primate habitats (particularly for gorillas and chimpanzees) are under immense pressure from deforestation and forest fragmentation.

This study has demonstrated that using remote sensing analysis combined with predictive modeling tools (such as Markovian and Maxent models) provides better understanding of forest transition and corresponding effects on primate habitats across parts of Africa. The approach presented in this study is a cost effective and time saving method of accurately predicting endangered primate habitats and understanding the dynamics of forest change and structure in the area. The information derived using this approach would assist conservation organizations, wildlife managers and the Government of Nigeria in making decisions and implementing policies that would help protect the forests and conserve endangered primates and other wildlife that are forest dependent for their existence.

In conclusion, the continued conservation of forests across African countries is paramount, as gorillas and chimpanzees alike depend on forest for survival. Hence, the only way to ensure their survival is to fight for the conservation of remaining forests. Such efforts will require support from government of African nations, Conservation Organizations, World Donor Agencies and most important the assistance of communities where such forests and endangered primates are found. The place of financial independence of forest protected areas can be promoted through ecotourism and infrastructure development [48]. Furthermore, implementing simple non-capital intensive and sustainable projects on a local scale can promote self-sufficiency across forest dependent communities in Nigeria.

\section{Acknowledgements}

The authors would like to appreciate Wildlife Conservation Society (Cross River) for providing the relevant field data on endangered primates across the study area and National Space Research and Development Agency (NASRDA) for making available the UK-DMC satellite image of Cross River State for image analysis.

\section{References}

[1] Al-Quraishi, A.M.F., Guang, D.H. and Jian, G.C. (2004) Land Degradation Detection, Mapping, and Monitoring in the Northwestern Part of Hebei Province, China, Using RS and GIS Technologies. Map Asia Conference 2004, Beijing, 26-29 August 2004.

[2] Angelsen, A. and Kaimowitz, D. (1999) Rethinking the Causes of Deforestation: Lessons from Economic Models. The World Bank Research Observer, 14, 73-98. http://dx.doi.org/10.1093/wbro/14.1.73

[3] Baldwin, R.A. (2009) Use of Maximum Entropy Modeling in Wildlife Research. Entropy, 11, 854-66. http://dx.doi.org/10.3390/e11040854

[4] Bergl, R.A., Brenda, J.B, Nsubuga, A. and Vigilant, L. (2008) Effects of Habitat Fragmentation, Population Size and Demographic History on Genetic Diversity: The Cross River Gorilla in a Comparative Context. American Journal of Primatology, 70, 848-59. http://dx.doi.org/10.1002/ajp.20559

[5] Bergl, R.A., Ymke, W., Aaron, N., Dunn, A., Inaoyom, I., Jacqueline, L. Sunderland-Groves and Oates, J.F. (2012) Remote Sensing Analysis Reveals Habitat, Dispersal Corridors and Expanded Distribution for the Critically Endangered Cross River Gorilla Gorilla gorilla diehli. Oryx, 46, 278-89. http://dx.doi.org/10.1017/S0030605310001857

[6] Boyd, D.S., Foody, G.M. and Ripple, W.J. (2002) Evaluation of Approaches for Forest Cover Estimation in the Pacific Northwest, USA, Using Remote Sensing. Applied Geography, 22, 375-92. http://dx.doi.org/10.1016/S0143-6228(02)00048-6

[7] Chander, G., Markham, B.L. and Helder, D.L (2009) Summary of Current Radiometric Calibration Coefficients for 
Landsat MSS, TM, ETM+, and EO-1 ALI Sensors. Remote sensing of Environment, 113, 893-903. http://dx.doi.org/10.1016/j.rse.2009.01.007

[8] Cowlishaw, G. and Dunbar, R.I.M (2000) Primate Conservation Biology. University of Chicago Press, Chicago.

[9] Elith, J., Graham, C.H., Anderson, R.P., Dudík, M., Ferrier, S., Guisan, A., Hijmans, R.J., Huettmann, F., Leathwick, J.R., Lehmann, A., Li, J., Lohmann, L.G., Loiselle, B.A., Manion, G., Moritz, C., Nakamura, M., Nakazawa, Y., Mc Overton, J., Peterson, A.T. and Phillips, S.J. (2006) Novel Methods Improve Prediction of Species’ Distributions from Occurrence Data. Ecography, 29, 129-51. http://dx.doi.org/10.1111/j.2006.0906-7590.04596.x

[10] ESRI (2014) ArcGIS Desktop: Release 10.2. Environmental Systems Research Institute. http://www.esri.com/

[11] FAO (2010) Global Forest Resources Assessment 2010. Food and Agriculture Organization of the United Nations, Rome.

[12] Geist, H.J. and Lambin, E.F. (2001) What Drives Tropical Deforestation. LUCC Report Series No. 4, 116 p.

[13] Harcourt, A.H., Stewart, K.J. and Inahoro, I.M. (1989) Gorilla Quest in Nigeria. Oryx, 23, 7-13. http://dx.doi.org/10.1017/S0030605300022535

[14] Harcourt, A.H. (1996) Is the Gorilla a Threatened Species? How Should We Judge? Biological Conservation, 75, 165176. http://dx.doi.org/10.1016/0006-3207(95)00059-3

[15] Harcourt, A.H. and Doherty, D.A. (2005) Species-Area Relationships of Primates in Tropical Forest Fragments: A Global Analysis. Journal of Applied Ecology, 42, 630-637. http://dx.doi.org/10.1111/j.1365-2664.2005.01037.x

[16] Huang, C., Wylie, B., Yang, L., Homer, C. and Zylstra, G. (2002) Derivation of a Tasselled Cap Transformation Based on Landsat 7 At-Satellite Reflectance. International Journal of Remote Sensing, 23, 1741-1748. http://dx.doi.org/10.1080/01431160110106113

[17] Imong, I., Eban, J. and Mengnjo, C. (2014) Using Technology to Save Gorillas in the Mbe Mountains. Gorilla Journal, 48, 15-17.

[18] Iqbal, M. (2012) An Introduction to Solar Radiation. Elsevier, Amsterdam.

[19] Irish, R.R. (2000) Landsat 7 Science Data User’s Handbook. National Aeronautics and Space Administration, Report 430-15-01-003-0.

[20] Ite, U.E. and Adams, W.M. (1998) Forest Conversion, Conservation and Forestry in Cross River State, Nigeria. Applied Geography, 18, 301-314. http://dx.doi.org/10.1016/S0143-6228(98)00023-X

[21] Kehinde, A.L., Akande, J.A. and Ntabe, E. (2009) Forest Stakeholder's Awareness of Reduced Impact Logging (RIL) in Nigeria and Cameroon. Journal of Horticulture and Forestry, 1, 176-181.

[22] Lu, D., Mausel, P., Brondizio, E. and Moran, E. (2002) Assessment of Atmospheric Correction Methods for Landsat TM Data Applicable to Amazon Basin LBA Research. International Journal of Remote Sensing, 23, 2651-2671. http://dx.doi.org/10.1080/01431160110109642

[23] Mambo, J. and Archer, E. (2007) An Assessment of Land Degradation in the Save Catchment of Zimbabwe. Area, 39, 380-391. http://dx.doi.org/10.1111/j.1475-4762.2007.00728.x

[24] McGarigal, K., Cushman, S.A., Neel, M.C. and Ene, E. (2002) FRAGSTATS: Spatial Pattern Analysis Program for Categorical Maps.

[25] Mengnjo, C. (2015) Wildlife Conservation Society Annual Report 2014—Cross River National Park (Okwangwo Divison). Wildlife Conservation Society. www.wcsnigeria.org

[26] Midha, N. and Mathur, P.K. (2010) Assessment of Forest Fragmentation in the Conservation Priority Dudhwa Landscape, India Using FRAGSTATS Computed Class Level Metrics. Journal of the Indian Society of Remote Sensing, 38, 487-500. http://dx.doi.org/10.1007/s12524-010-0034-6

[27] Mondal, P. and Southworth, J. (2010) Evaluation of Conservation Interventions Using a Cellular Automata-Markov Model. Forest Ecology and Management, 260, 1716-1725. http://dx.doi.org/10.1016/j.foreco.2010.08.017

[28] Morgan, B.J., Adeleke, A., Bassey, T., Bergl, R., Dunn, A., Fotso, R., Gadsby, E., Gonder, K., Greengrass, E., Koulagna, D.K., Mbah, G., Nicholas, A., Oates, J., Omeni, F., Saidu, Y., Sommer, V., Sunderland-Groves, J., Tiebou, J. and Williamson, E. (2011) Regional Action Plan for the Conservation of the Nigeria-Cameroon Chimpanzee (Pan troglodytes ellioti). IUCN/SSC Primate Specialist Group and Zoological Society of San Diego.

[29] Myers, N., Mittermeier, R.A., Mittermeier, C.G., Da Fonseca, G.A.B. and Kent, J. (2000) Biodiversity Hotspots for Conservation Priorities. Nature, 403, 853-858. http://dx.doi.org/10.1038/35002501

[30] Oates, J.F., Bergl, R.A. and Linder, J.M. (2004) Africa’s Gulf of Guinea Forests: Biodiversity Patterns and Conservation Priorities. Advances in Applied Biodiversity Science, Vol. 6, Conservation International, Washington DC.

[31] Oates, J.F., White, D., Gadsby, E.L. and Bisong, P.O. (1990) Conservation of Gorillas and Other Species. In: Caldecott, J.O., Oates, J.F. and Ruitenbeek, H.J., Eds., Cross River National Park (Okwangwo Division): Plan for Developing the 
Park and Its Support Zone, Appendix 1, WWF-UK, Goldalming.

[32] Oates, J.F., Sunderland-Groves, J., Bergl, R., Dunn, A., Nicholas, A., Takang, E., Omeni, F., Imong, I., Fotso, R. and Nkembi, L. (2007) Regional Action Plan for the Conservation of the Cross River Gorilla (Gorilla gorilla diehli). IUCN/SSC Primate Specialist Group and Conservation International, Washington DC.

[33] Oyebo, M., Bisong, F. and Morakinyo, T. (2015) A Preliminary Assessment of the Context for REDD in Nigeria. http://www.gcftaskforce.org/meeting/documents/Nigeria_National_Update_GCF_2011.pdf

[34] Phillips, S.J., Anderson, R.P. and Schapire, R.E. (2006) Maximum Entropy Modeling of Species Geographic Distributions. Ecological Modelling, 190, 231-259. http://dx.doi.org/10.1016/j.ecolmodel.2005.03.026

[35] Phillips, S.J., Dudík, M. and Schapire, R.E. (2004) A Maximum Entropy Approach to Species Distribution Modeling. Proceedings of the 21st International Conference on Machine Learning, Banff, 4-8 July 2004, 83. http://dx.doi.org/10.1145/1015330.1015412

[36] Plumptre, A.J., McNeilage, A., Hall, J.S. and Williamson, E.A. (2002) The Current Status of Gorillas and Threats to Their Existence at the Beginning of a New Millennium. In: Taylor, A.B. and Goldsmith, M.L., Eds., Gorilla Biology: A Multidisciplinary Perspective, Cambridge University Press, Cambridge, 414-431. http://dx.doi.org/10.1017/cbo9780511542558.019

[37] Radespiel, U. and Bruford, M.W. (2014) Fragmentation Genetics of Rainforest Animals: Insights from Recent Studies. Conservation Genetics, 15, 245-260. http://dx.doi.org/10.1007/s10592-013-0550-3

[38] Ravilious, C., Kapos, V., Osti, M., Bertzky, M., Bayliss, J.L., Dahiru, S. and Dickson, B. (2010) Carbon, Biodiversity and Ecosystem Services: Exploring Co-Benefits. Nigeria: Preliminary Results. UNEP-WCMC, Cambridge, UK.

[39] Saatchi, S., Buermann, W., ter Steege, H., Mori, S. and Smith, T.B. (2008) Modeling Distribution of Amazonian Tree Species and Diversity Using Remote Sensing Measurements. Remote Sensing of Environment, 112, 2000-2017. http://dx.doi.org/10.1016/j.rse.2008.01.008

[40] Schoneveld, G.C. (2014) The Politics of the Forest Frontier: Negotiating between Conservation, Development, and Indigenous Rights in Cross River State, Nigeria. Land Use Policy, 38, 147-162. http://dx.doi.org/10.1016/j.landusepol.2013.11.003

[41] Shoch, D., Eaton, J. and Settelmyer, S. (2011) Project Developer’s Guidebook to VCS REDD Methodologies. Conservation International, Arlington.

[42] Smith, P., Bustamante, M., Ahammad, H., Clark, H., Dong, H., Elsiddig, E.A., Haberl, H., Harper, R., House, J., Jafari, M., Masera, O., Mbow, C., Ravindranath, N.H., Rice, C.W., Robledo Abad, C., Romanovskaya, A., Sperling, F. and Tubiello, F. (2014) Agriculture, Forestry and Other Land Use (AFOLU). In: Edenhofer, O., Pichs-Madruga, R., Sokona, Y., Farahani, E., Kadner, S., Seyboth, K., Adler, A., et al., Eds., Climate Change 2014: Mitigation of Climate Change. Contribution of Working Group III to the Fifth Assessment Report of the Intergovernmental Panel on Climate Change, Cambridge University Press, Cambridge, United Kingdom and New York, 811-922.

[43] Fielding, A.H. and Bell, J.F. (1997) A Review of Methods for the Assessment of Prediction Errors in Conservation Presence/Absence Models. Environmental Conservation, 24, 38-49. http://dx.doi.org/10.1017/S0376892997000088

[44] Souza, C., Firestone, L., Silva, L.M. and Roberts, D. (2003) Mapping Forest Degradation in the Eastern Amazon from SPOT 4 through Spectral Mixture Models. Remote Sensing of Environment, 87, 494-506. http://dx.doi.org/10.1016/j.rse.2002.08.002

[45] CRS (2014) Cross River State of Nigeria Gazette. C.R.M. Court, Ed., No. 1, Ministry of Information, Calabar.

[46] Suter, J. and Oates, J. (2000) Sanctuary in Nigeria for Possible Fourth Subspecies of Gorilla. Oryx, 34, 71-71. http://dx.doi.org/10.1017/S0030605300030921

[47] Takada, T., Miyamoto, A. and Hasegawa, S.F. (2010) Derivation of a Yearly Transition Probability Matrix for LandUse Dynamics and Its Applications. Landscape Ecology, 25, 561-572. http://dx.doi.org/10.1007/s10980-009-9433-x

[48] Ezebilo, E.E. and Mattsson, L. (2010) Socio-Economic Benefits of Protected Areas as Perceived by Local People around Cross River National Park, Nigeria. Forest Policy and Economics, 12, 189-193. http://dx.doi.org/10.1016/j.forpol.2009.09.019 